\title{
Pattern Recognition of the Herbal Drug, Magnoliae Flos According to their Essential Oil Components
}

\author{
Eun Sook Jeong, ${ }^{,}$Kyu-Yeol Choi, ${ }^{+, 8}$ Sun-Chun Kim, ${ }^{+, "}$ In Seop Son, ${ }^{,}$Hwang Eui Cho, \\ Su Youn Ahn, ${ }^{\dagger, *}$ Mi Hee Woo, ${ }^{\ddagger}$ Jin Tae Hong, ${ }^{\dagger}$ and Dong Cheul Moon ${ }^{+,}$ \\ College of Pharmacy, Chungbuk National Lnwersity, Cheongiu 362-763, Korea. E-mail donoonatchmgbukac.kr

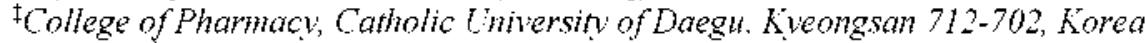 \\ SSeoul Perfimery Co. LTD, Seocho-gu, Seoul 137-808, Korea \\ "National Institute of Scientific Investigation. Korea \\ Received February 6, 2009, Accepted Harch 25, 2009
}

\begin{abstract}
This paper describes a pattern recognition method of Hagnoliae flos based on a gas chromatographic/mass spectrometric (GC/MS) analy sis of the essential oil components. The botanical drug is mainly comprised of the four magnolia species (M. dentata. M. biondi, M. kobus, and M. lifflora) in Korea, although some other species are also being dealt with the drug. The GC/MS separation of the volatile components, which was extracted by the simultaneous distillation and extraction (SDE), was performed on a carbowax column (supelcowax 10:30 $\mathrm{m} \times 0.25$ num $\times 0.25 \mu \mathrm{m}$ ) using temperature programning. Variance in the retention times for all peaks of interests was within RSD $2 \%$ for repeated analyses $(n=9)$. Of the 74 essential oil components identified from the magnolia species, approximately 10 major components, which is $\alpha$-pinene, $\beta$-pinene, sabinene, myrcene, $d$-limonene, eucarly ptol (1,8-cineol), $\gamma$-terpinene, $p$-cymene, linalool, $\alpha$-terpineol, were commonly present in the four species. For statistical analysis, the original dataset was reduced to the 13 variables by Fisher criterion and factor analysis (FA). The essential oil pattems were processed by means of the nultivariate statistical analy sis including hierarchical cluster analy'sis ( $\mathrm{HC}^{-} \mathrm{A}$ ), principal component analysis (PCA) and discriminant analysis (DA). All samples were divided into four groups with three principal components by PCA and according to the plant origins by HCA. Thirty-three samples ( 23 training sets and 10 test samples to be assessed) vere correctly classified into the four groups predicted by PCA. This method would provide a practical strategy for assessing the authenticity or quality of the well-known herbal drug, hagnoliae flos.
\end{abstract}

Key Wonds: Magnoliae flos, M. biondit. M. dentrdata. GC/MS. Multivariate statistical analysis

\section{Introduction}

Magnoliae flos (M. flos: the dried flower buds of Magnolia denudata or related species) is a botanical drug officially listed in the Pharmacopoeia of Asian countries. The drug name is called as Shin-Yi in Korea and Japan, Xin-Yi in China. The herbal drug has been used for managing nasal conjestion with headache, sinusitis and allergic rhinitis. ${ }^{1.2}$ It has also a wide range of pharmacological effects including antirheumatic ${ }^{3}$ antiangiogenic, ${ }^{4}$ antiallergic. ${ }^{5-8}$ antiinflammatory. ${ }^{5-10}$ and anitmicrobial activities. ${ }^{11}$

Essential oil components of mono- and sesquiterpenes. and many lignans are the pharmacologically active ingredients of mognolia drugs. ${ }^{12-15}$ As major volatile components. bornyl acetate. eucarlyptol (1. 8-cineol), $\alpha$-pinene. and eudesmol showed anti-inflammatory effects. Other components. such as camphor, cymene linalool. limonene myrcene $\alpha$-pinene. $\beta$-pinene. terpinene. nerolidol and citral may contribute to the antimicrobial actions of $M$. flos.

The four species, M. biondit, $M$ dentdata, M. kobus, and $M$. Iififora, are the well-known herbs in Korea. but others. such as M. sprengeri and M. sargentiona in China and M. salicifolia in Japan. are also treated as 1 . flos or substitutes in the respective countries. Therefore they could be misused especially when these are traded among the countries. Because the remedy and prescription should be different depending on plant species. accurate identification of the species origin is essential to assure the quality of drug in clinical applications. No reports are available for the chemical discrimination of M. flos as the herbal drug to date.

We established a GC/MS pattern recognition method based on the volatile components extracted using a simultaneous distillation and extraction (SDE). which is a popular method in analysis of essential oils. ${ }^{1.12}$ The classification model for four different Magnoliae flos were successfully established by the multivariate statistical analysis i.e... hierarchical cluster analysis $(\mathrm{HCA})$. principal component analysis ( $\mathrm{PCA})$ and discrininant analysis (DA).

\section{Experimental Section}

Plant materials. Twenty specimens of $M$. flos ( $3 \mathrm{M}$. biondii, 8 \%. denudata. $3 \mathrm{M}$ kobus, 3 M. lilifora. M. denudata var. purpurascens, A. hilifora var. gracilis and M. salicifolia' were collected from Korea and China during March to April 2008. The 20 reference specimens identified were used. The 9 drugs $(\mathrm{U}-1 \sim \mathrm{U}-9)$ were purchased from oriental herbal stores in Korea. and 7 samples (U-10 U-16) were obtained from Daegu Catholic University. and dried under air prior to analysis. (Table 1)

Chemicals. All standard of essential oils were provided by Seoul Perfumery Co. LTD (Seoul. Korea). The HPLC-grade diethyl ether was purchased from J. T. Baker Co. (Phillipsburg. USA) and distillated. All other solvents employed were of 
Table 1. Magnoliae flos (Shin-Yi) samples

\begin{tabular}{|c|c|c|}
\hline Label & Magnoliae flos & Source \\
\hline$B-1$ & 11. biondii & Henan, China \\
\hline $\mathrm{B}-2$ & 11. biondii & Daegu, Korea \\
\hline$B-3$ & M. biondii & Yangsan, Korea \\
\hline D-1 & 1. dentadata & Yangsan, Korea \\
\hline $\mathrm{D}-2$ & 11. dentidata & Gyungilu, Korea \\
\hline D-3 & 11. dentidata & Youngcheon, Korea \\
\hline $\mathrm{D}-4$ & 11. dentidata & Cheongju, Korea \\
\hline D-5 & 11. dentidata & Cheongju, Korea \\
\hline D-6 & 11. dentidata & Cheongju, Korea \\
\hline D-7 & 11. dentidafa & Daegu, Korea \\
\hline D-8 & 1. demudata & Gyungju, Korea \\
\hline $\mathrm{K}-1$ & M. kobus & Seoul, Korea \\
\hline $\mathrm{K}-2$ & 11. kobus & Cheongju, Korea \\
\hline $\mathrm{K}-3$ & 1. kobus & Cheongjul, Korea \\
\hline L-1 & 1. Hiflora & Cheongju, Korea \\
\hline $\mathrm{L}-2$ & 11. lilifora & Daegu, Korea \\
\hline$L-3$ & 1. Hifflora & Daegu, Korea \\
\hline $\mathrm{P}$ & 1. demudata var purpurascens & Youngcheon, Korea \\
\hline $\mathrm{S}$ & 1. hitflora var gracilis & Elumseong, Korea \\
\hline $\mathrm{G}$ & M. salicifolia & Daejeon, Korea \\
\hline $\mathrm{U}-1$ & herbal drug & Seoul, Korea \\
\hline $\mathrm{U}-2$ & herbal drug & Daegu, Korea \\
\hline $\mathrm{U}-3$ & herbal drug & Seoul, Korea \\
\hline $\mathrm{U}-4$ & herbal drug & Seoul, Korea \\
\hline $\mathrm{U}-5$ & herbal drug & Seoul, Korea \\
\hline $\mathrm{U}-6$ & herbal drug & Seoul, Korea \\
\hline $\mathrm{U}-7$ & herbal drug & Youngcheon, Korea \\
\hline $\mathrm{U}-8$ & herbal drug & Youngcheon, Korea \\
\hline U-9 & herbal drug & Youngcheon, Korea \\
\hline $\mathrm{U}-10$ & plant sample & Daegu, Korea \\
\hline U-11 & plant sample & Daegu, Korea \\
\hline $\mathrm{U}-12$ & plant sample & Daegu, Korea \\
\hline $\mathrm{U}-13$ & plant sample & Daegu, Korea \\
\hline $\mathrm{U}-14$ & plant sample & Daegu, Korea \\
\hline $\mathrm{U}-15$ & plant sample & Daegu, Korea \\
\hline $\mathrm{U}-16$ & plant sample & Daegu, Korea \\
\hline
\end{tabular}

analytical grade quality and were redistilled before use. Anhydrous sodium sulfate was purchased from Samchun Chemical (Py̧eongtak. Korea).

Sample preparation. The volatile components from $\mathrm{M}$. flos ( 2 g sample plus $100 \mathrm{~mL}$ of distilled water) were extracted into $40 \mathrm{~mL}$ diethyl ether for $2 \mathrm{hr}$ using a Likens-Nickerson's type SDE apparatus (Kontes. Vineland, NJ. USA). After cooling the extracts to ambient temperature $(30 \mathrm{~min})$. the solvent phase was collected and dried over anlydrous sodium sulfate in a refrigerator for one day to remove residual water. The extract was carefully concentrated to about $2 \mathrm{~mL}$ at $40^{\circ} \mathrm{C}$ using a rotary evaporator at atmospheric pressure, and then finally concentrated to $1.0 \mathrm{~mL}$ under gentle nitrogen flow.

GC/MS analysis. GC/MS analyses were performed with an
Agilent 7890 series GC sy stem coupled to an Agilent $5975 \mathrm{~B}$ inert MSD (Agilent. CA. USA). A supelcowax 10 column ( 30 $\mathrm{m} \times 0.25 \mathrm{~mm} \times 0.25 \mu \mathrm{m}$ film thickness. Bellefonte. USA) was used for the GC separation. One nicro-liter aliquots of each sample extracts was injected into the GC column with split (80:1). The GC oven temperature was initially set at $70^{\circ} \mathrm{C}$ (hold $5 \mathrm{~min}$ ) and ramped to $240^{\circ} \mathrm{C}$ (hold $20 \mathrm{~min}$ ) at $3^{\circ} \mathrm{C} / \mathrm{min}$. Helium was used as a carrier gas at $1.0 \mathrm{~mL} / \mathrm{min}$. The injector temperature was set at $250^{\circ} \mathrm{C}$ and the temperature of the ion source and the interface were $230^{\circ} \mathrm{C}$ and $280^{\circ} \mathrm{C}$. respectively. Ionization energy was set to $70 \mathrm{eV}$ and the mass range in scanning mode was $\mathrm{m} / 235-400$. Inherent peaks were identified using the Mass spectral search program (Wiley library $8 \mathrm{~N} 05 \mathrm{ST}$ ) and/or the library. "Identification of Essential oil Components by GC/MS. $4^{\text {dh }}$ Edition (Allured. 2007)" combined with home-made data base.

Temperature-programmed retention indices (TPRIs). which seem to be more useful in the practice of essential oils analysis. are varied in different chromatographic operating conditions such as carrier flow-rate and temperature program. The following quasi-linear equation proposed by van den Dool and Kratz ${ }^{\&}$ was used to calibrate and build a TPRI database of natural volatile components.

Method validation. To check the reproducibility. three QC samples (D-7. U-4 and U-8) were analyzed repeatedly three times per sample on three separate days $(n=9)$. Variance in the retention times for all peaks of interests was within RSD $2 \%$. The variance in percent peak area was less than RSD 30\% for high-intensity peaks but was slightly higher than RSD $\mathbf{5 0 \%}$ for low-intensity peaks, which might be unavoidable for analysis of crude plant materials after SDE extraction on separate days.

Statistical analysis. Thirteen peaks according to Fisher criterion were selected as components for data analysis. Multivariate statistical analysis, HCA. PCA and DA. were performed using the statistical package. SPSS (version 12.0 . SPSS Inc., Chicago. USA). The HCA was performed by Ward's method using squared Euclidian distance as a measure of similarity. For PCA analysis. the eigenvalues of $>1.0$ obtained by Kaiser and the cumulative proportion of eigenvalues of $\geq 80 \%$ were considered sufficiently conspicuous for interpretation. The DA was performed to develop a classification model from the model subsequently validated.

\section{Results and Discussion}

Volatile components from Magnoliae flos. Figure 1 shows GC/MS chromatograms of the four $H$ flos $(M$, biondii, $M$. denudata, 1 . kobus and 1 . liliflora). The chromatographic profiles were obviously different from each other s chromatogram depending on the plant origins. Although we identified total 157 inherent peaks from the $36.1 \%$ flos samples tested. the 83 components were included of trace (their relative intensity $\leq 0.05 \%$ ) in $1 /$ fos samples or were detected in some few of the same species. Therefore. we selected only the 74 components that comprise more than $0.05 \%$ or have characteristics for the species. Table 2 shows the 74 components listed according to their elution order on a carbowax column 

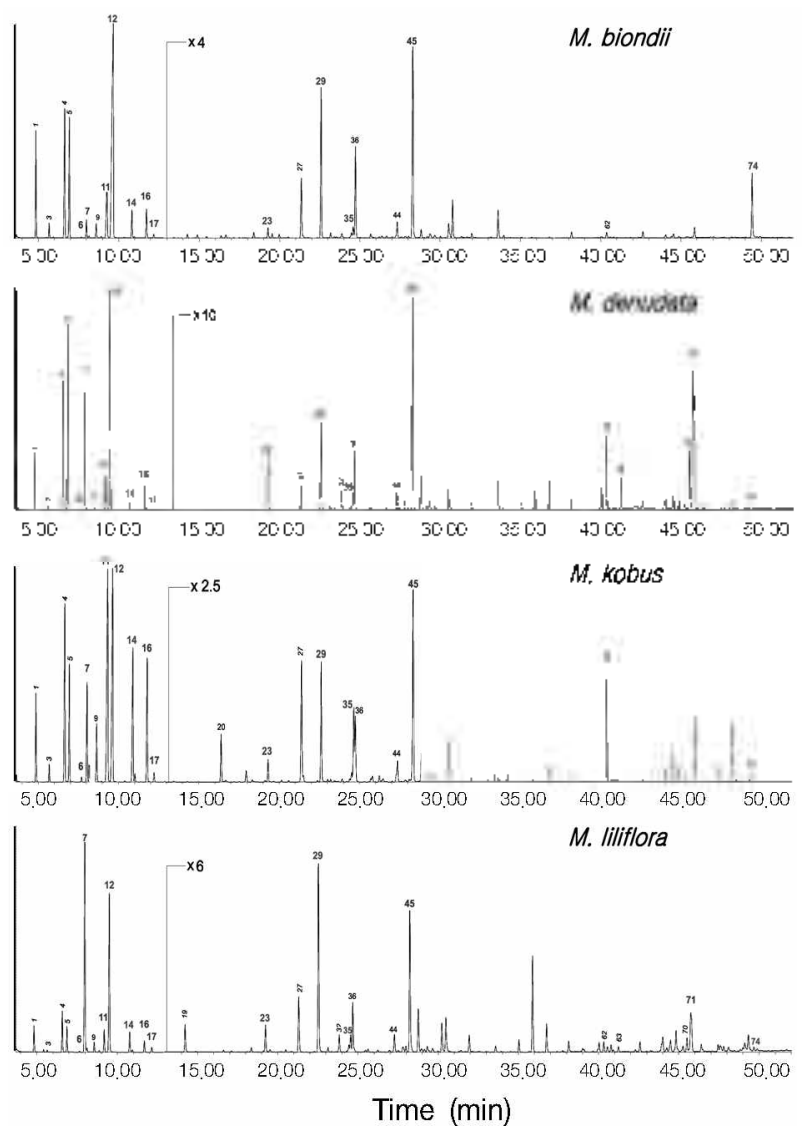

Figure 1. Representative GC/MS chromatogranns of Magnoliae fos species.

with their relative peak areas of the total oil components. The main components comprising the mono-. sesquiterpenes and their oxides showed the content in the range of $80.4 \sim 85.4 \%$ for M. biondii. $79.0 \sim 91.9 \%$ for M. denudata. $78.9 \sim 90.0 \%$ for $M$. kobus, and $82.3 \sim 87.8 \%$ for . hilifora. Our components study showed the similar result with the previous report ${ }^{19}$ on the essential oil components from the three kinds of magnolia species ( $M$. biondii, $M$. dentdata and $M$. sprengeri) that the main components were found to be eucarlyptol (1. 8-cineole). sabinene, $\beta$-pinene. $\alpha$-pinene, trans-caryophyllene.

In the present study, some components were present with remarkably large content from one or two species. i.e.. farnesol (74) in $M$. biondii; terpinen-4-ol (36) in $M$. denudata: $\beta$ -caryophyllene (35), ód-cadinene (52) 1.6-germacradien-5-ol (62) in M. kobus; camphor (27), $\mathrm{t}$-muurolol (72) in both $M$. biondii and $M$. kobus: terpinen-4-ol (36) and $\beta$-eudesmol (71) in both $M$. dentudato and $M$. lififora. It was noticeable that a few components represent the plant specificities irrelevant to their content: citronellal (25). geranyl acetate (59) and methyl isoeugenol (67) were detected only in M. biondii: $\alpha$-eudesmol (70) and $\beta$-eudesmol (71) in both $M$. dentidata and $M$. filiflora: 2-nonanone (20) in both M. biondii and M. kobus.

Principal component analysis (PCA). Of the 74 components represented in Table 2. some components showed large difference of the content within the same species because of the place of origin. harvest time dryness condition. etc. Therefore. the components for statistical analy sis were selected

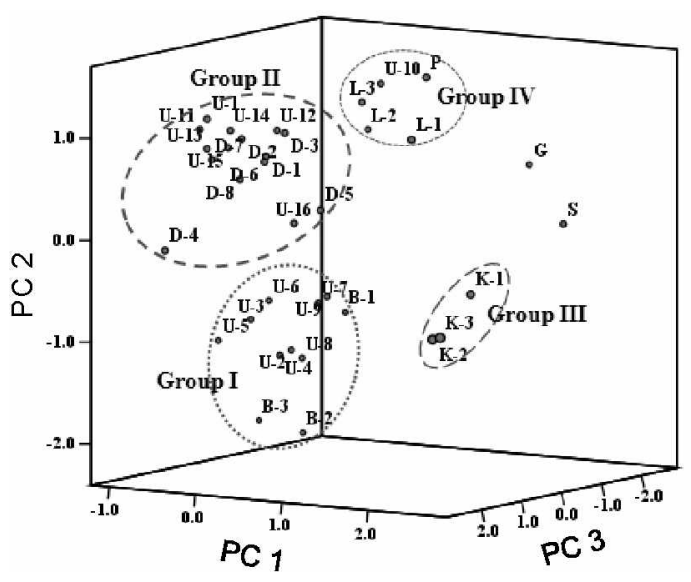

Figure 2. Score plot by principal component analysis (PCA) of 36 magnolia samples.

by Fisher method ${ }^{20}$ a coefficient based on the between- and within-group variations. The higher the value of Fisher coefficient is the better variable. The 13 components, which are equal to the number of the principal factors. were determined by the PCA of the 74 components. The Fisher coefficients for the selected 13 components were as follows: 139.8 (myrcene): 96.6 ( $d$-limonene): 39.7 ( $\beta$-eudesmol): 39.4 (ô-3-carene); 37.1 ( $\beta$-caryoplyllene): 24.6 (terpinolene); 19.5 ( $\gamma$-terpinene): 16.7 (p-cymene): 11.6 (encalyptol): 11.3 (farnesol): 9.7 (transsabinene hydrate): 3.3 (linalool): 2.6 ( $\alpha$-terpineol). Prior to the PCA analysis. the suitability of the data for factor analysis was checked. The Kaiser-Meyer-Olkin measure of sampling adequacy was 0.61 exceeding the recommended value $(0.6)^{-1}$, that means the matrix is appropriate for PCA. The four principal components with eigenvalues exceeding one were extracted according to the Kaiser criterion, which explains up to $81.7 \%$ of the total variance. The $1^{\text {st }}-4^{\text {dh }}$ principal components were responsible for $39.8 \% .19 .1 \%, 13.5 \%$ and $9.4 \%$ of the entire information. respectively: The first factor was mainly influenced by the conponents with the factor loadings $>0.5$ were $\hat{\delta}$-3-carene. $d$-limonene encalyptol. $\gamma$-terpinene. $p-c y m e n e$. terpinolene, trans-sabinene hydrate. $\beta$-caryophyllene, $\alpha$-terpineol. The second factor was closely related to my rcene. $\beta$-eudesmol. farnesol. Likewise. the third factor is related to terpinolene. $\beta$-caryophyllene. and the fourth factor is related to linalool

The score plot of the first three principal components (Figure 2) showed the clear differentiation of the species. From the scatter points, the samples could be classified into four groups. which were marked as group I-IV according to the species: 1 . biondii (Group I): $M$. dentudata (Group II): $M$. kobus (Group III) and M. hilffora (Group IV). M. denudata var. purpurascens $(\mathrm{P})$ was clustered into group IV, while $M$. salicifolia $(\mathrm{S})$ and H. hliffora var. gracilis (G) were not clustered into any of the four groups. From the score values on the principal components for each species. it can be interpreted that the contents of $\delta$-3-carene (6). $d$-limonene (11). $\gamma$-terpinene (14), $p$-cymene (16). $\beta$-caryophyllene (35) on the first PC loadings are higher for $M$. kobus than the other species, while encalyptol (12), trans-sabinene hydrate (23), $\alpha$-terpineol 
Table 2. Chemical composition of the essential oils from Magnoliae flos specimens (min-mas; \%)

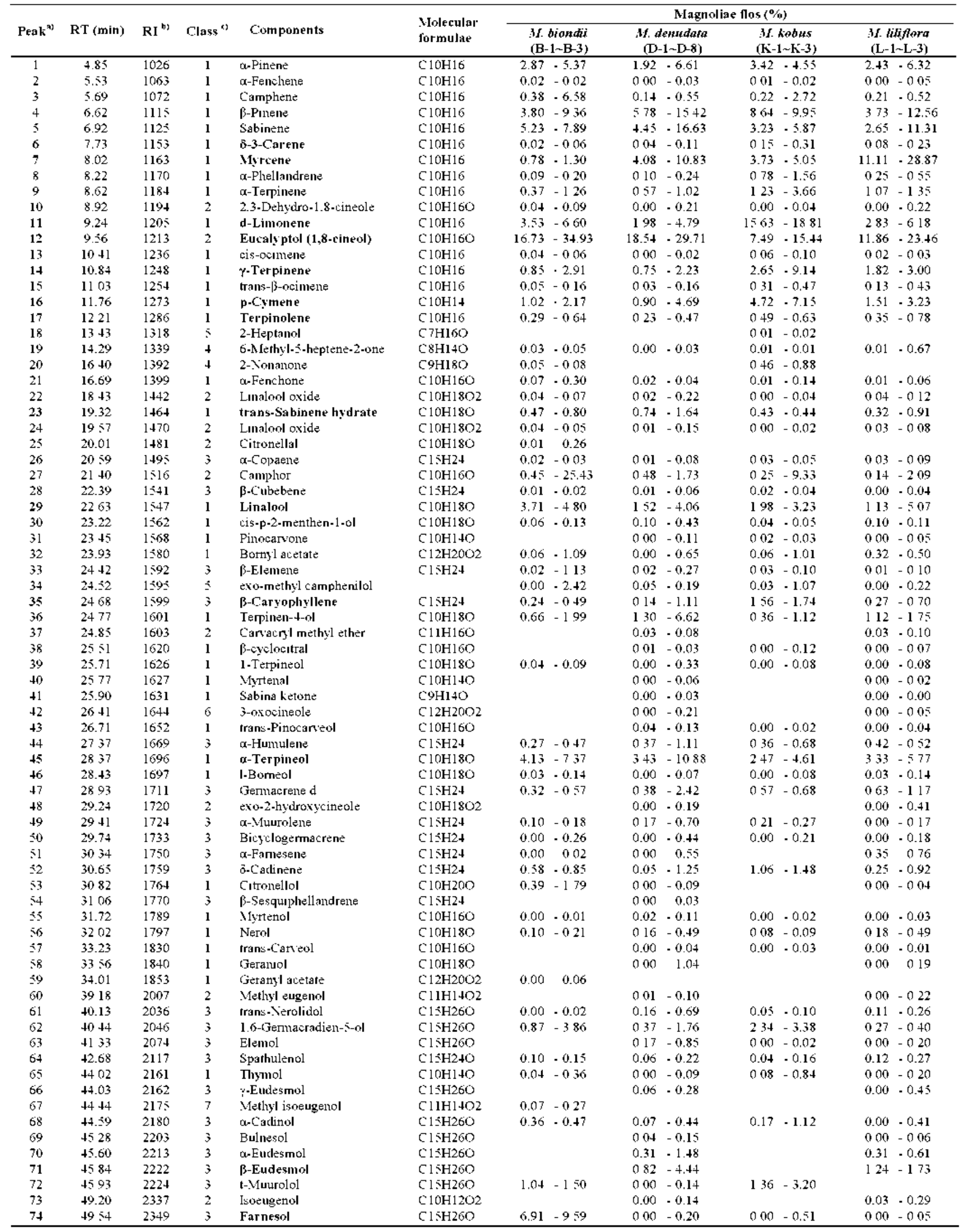

a) The bold-character number denote the peaks slected for statistical analysis. b) Retention index definded as showin in experim ental selection. c) Chemical class: 1. Monoterpene hydrocarbons: 2. Monoterpene oxiders: 3. Sesquiterpene hydrocarbons; 4. Ketones: 5. Alcohols; 6. Esters: 7. Ethers 


\section{Dendrogram using Ward Method}

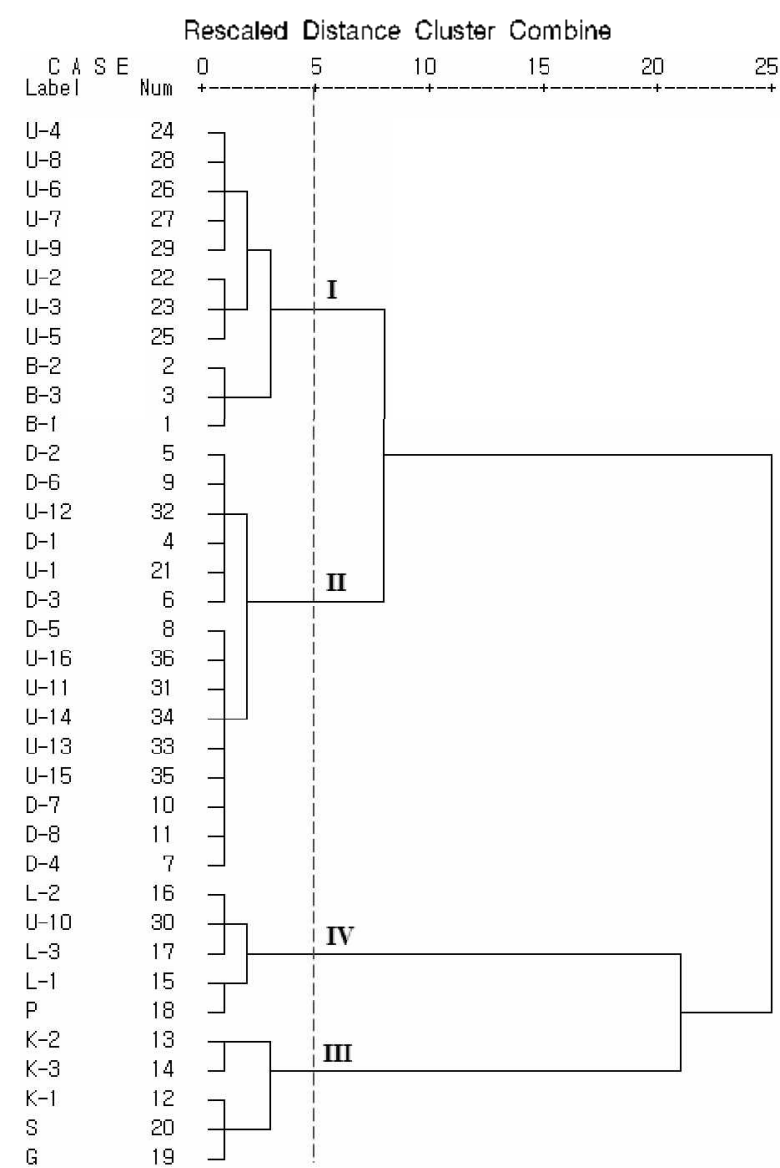

Figure 3. A Dendrogran of hierarchical cluster analy sis (HCA) of 36 itagnoline flos samples.

(45) are lower. From the second PC loadings. myrcene (7) showed the highest contents for M. Iilifora among the four species. and the content of farnesol (74) is highest for $M$. biondii. From the third PC loadings. terpinelone (17) showed the higher content both for M. salicifolia (S) and M. hiliflora var. gracilis $(\mathrm{G})$ than the other species. From the fourth $\mathrm{PC}$ loading. linalool (29) showed higher content for $\mathrm{M}$. biondii than the other species.

Hierarchical cluster analysis (HCA). The dataset for HCA was consisted of the 13 selected components and relative peak area for a total of the 36 magnolia samples. Dendrogram obtained from HCA was shown in Figure 3. The 36 samples were grouped into the predicted four clusters (I-IV): $M$. biondii (group I): M. dentdata (group II). M. kobus (group III) and $M$. lififora (group IV). The three species with each one specimen. M. saliciffora $(\mathrm{S})$ and M. hilffora var gracillis $(\mathrm{G})$ were grouped into group III. while M. denudata var. purpurascens (P) was classified into to the group IV.

Discriminant analysis (DA). DA was performed to develop a discrimination model of the + groups classified by the PCA using the relative peak area of the 13 selected components as input data. The four groups of the 33 samples determined by PCA are in the predicted groups. The three specimens (only one sample per species). M. denudata var. purpurascens $(\mathrm{P})$.

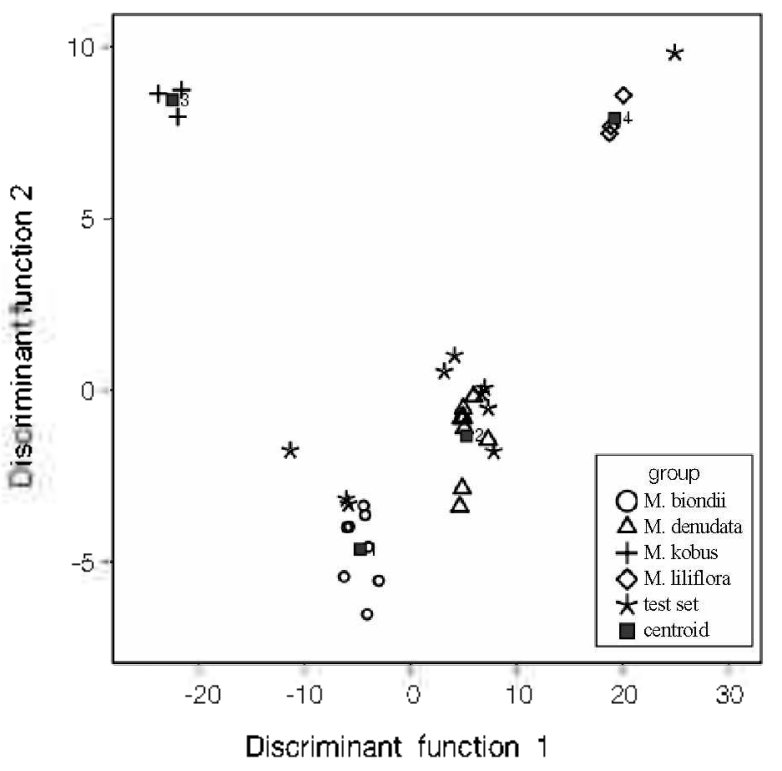

Figure 4. Discriminant analysis (DA) plots of the Hagnoliae flos samples on the space defined by the first two discriminant functions.

M. salicifolia $(\mathrm{S})$ and M. lilftora var. gracilis $(\mathrm{G})$. were not included in DA. Feature selection was performed by stepwise DA using a Wilk's Lambda selection criterion. The 8 featured components, $\delta$-3-carene (6), myrcene (7), $d$-limonen (11), eucalyptol (12), $\gamma$-terpinene (14), terpinolene (17), $\beta$-eudesmol (71), farnesol (74). were selected as the most important variables for differentiating the 4 groups of samples. All samples in the predicted groups by PCA were correctly classified $(100 \%)$. To deternine the predictive ability of the resulting model. 23 samples (training set consisting of $8 \mathrm{M}$. biondii, $9 \mathrm{M}$. denudata, $3 \mathrm{M}$ kobus. $3 \mathrm{M}$. lilifora) were selected at random to constnuct a DA model that could then be used to predict the group of remaining 10 samples (U-7 U- 16 , test set). A $100 \%$ correct classification was also obtained when the validation procedure was used. Figure 4 shows the 33 samples on the plane defined by the two discriminant functions obtained, and test set was represented as asterisks. The 10 test samples were classified in 11. biondi $(\mathrm{U}-7 \sim \mathrm{U}-9)$, 1. dentata (U-11 $\sim \mathrm{U}-16$ ). and H. Iilfora (U-10). The assignment of the 10 samples of test set permits to estimate the good possibilities of our procedure.

\section{Conclusion}

A GC/MS pattern recognition method based on the data of essential oil components successfully claracterized the herbal dnugs according to the four classes of plant origins. The method was able to facilitate discrinination of the fingerprint patterns from different $M$. flos samples. The 33 samples were classified into 4 groups by PCA and all group members determined by PCA were in the predicted group that $100 \%$ of all samples correctly classified by DA. This fingerprint pattern recognition would provide a practical strategy for assessing the authenticity or quality of the well-known herbal drug. H. flos. 
Acknowledgments. This work was supported by 2008 General subject support by Chungbuk National University. Republic of Korea

\section{References}

1. Bae K. In Hedicmal Plants of Kored: Kyll-Hak Press: Seoul, Korea, 2000.

2. Benskv, D.: Gamble, A. In Chinese Herbal hedicined Hateria Medic); Eastland Press: Washington, U.S.A., 1993

3. Kobayashi, S.: Kobayashi. H.: Matsuno. H.: Kimnta, I.: Kinnura, M. Inmminophamacol. $1998,39,139$

4. Kobayashi, S.; Kimura, I.; Kimura, M. Biol. Phom. Bull. 1996, 19.1304.

5. Shen, Y: Pang, E. C. K.: Xue C. C. L.: Zhao, Z Z : Lin, J. G.: Li, C. G. Photontedicine 2008, 15, 808 .

6. Lenon, G. B: Li, C. G.: Xue, C. C.; Thien, F. C. Stroy, D. F. $J$. Ethophannacol. 2008, 116,547

7. Kin. H. M: Yi. J. M.: Lim. K. S. Phamacol Res. 1999,39, 107.

8. Kim, G. C.; Lee, S. G.; Park, B. S. Int Atch. Allerg, Inmmol. 2003, 131, 101.
9. Kang. T. S.: Lee K. H.: Han, M. H.: Lee. H. T.; Aln, T. M.; Han, S. B.; Han, G. H.; Lee, K. H.: Park, S. K.; Kim, H. M. Phytother: Res. 2008, 22, 883.

10. Lim, J. P. Park, Y. S. Korean J. Medicinal Crop Sci. 2005, 15(6), 245.

11. Kim. Y. G. Wokchae Konghak 1999.27(1). 105.

12. Xu, Z. L.: Pan, J. G.: Zhao, Z. Z. Zhonggno Zhong Yao Za Zhi. $1989,1+(5), 294$

13. Wu, W. Zhong Yao Cai $\mathbf{2 0 0 0}, 23(9), 538$

14. Yang. J.: Xu, Z.: Pan, J.: Gi, L. Zhongguo Zhong Yao Za Zhi. $1998,23(5), 295$

15. Shen, Y; Li, C. G.; Zhou, S. F.; Pang, E. C. K.; Story, D. F.; Xue, C. C. L. Curr led. Chent $2008,15,1616$.

16. Godefroot, M.; Sandra, P.: Verzele, M. J. Chomatogr: 1981 , 203,325 .

17. Chaintreau, A. Flavour Frag. J. 2001, 16(2), 136

18. Dool, H. V. D.; Kratz, P. D. J. Chrontatogr: 1963, 11, 463.

19. Wu, W. Zhong Iao Cai. 2000, $23(9), 538$.

20. Gong. F.: Wang, B. T.; Liang Y. Z.; Chan, F. T.: Fung, Y. S. Anal. Chem . Acta 2006, 572, 265

21. Kaiser, H. F. Edic. Psichol. Heas, 1960, 20,141 